\title{
Plasma responses in human subjects after ingestions of multiple doses of natural $\alpha$-cryptoxanthin: a pilot study
}

\author{
Jörg Schlatterer ${ }^{1}$, Dietmar E. Breithaupt ${ }^{1}$, Maike Wolters ${ }^{2}$ and Andreas Hahn ${ }^{2}$ \\ ${ }^{1}$ Institute of Food Chemistry, University of Hohenheim, Garbenstrasse 28, 70593 Stuttgart, Germany \\ ${ }^{2}$ Institute of Food Science, University of Hannover, Wunstorfer Strasse 14, 30453 Hannover, Germany
}

(Received 7 February 2006 - Revised 10 April 2006 - Accepted 20 April 2006)

\begin{abstract}
Xanthophylls have attracted a lot of interest since their health benefits were documented. Unfortunately, studying their intestinal absorption is often affected by high baseline levels present in the fasting plasma. As $\alpha$-cryptoxanthin is rarely found in the traditional European diet, its concentration in human plasma is extremely low. A pilot human intervention study was designed using $\alpha$-cryptoxanthin for the first time as a marker xanthophyll in a minimally formulated cellulose-based supplement. $\alpha$-Cryptoxanthin was administered in gelatin soft-gel capsules in multiple doses of $156 \mu \mathrm{g} /$ $\mathrm{d}$ to three male volunteers (age 27.3 (SD 4.7) years; BMI $21.6(\mathrm{SD} 0.3) \mathrm{kg} / \mathrm{m}^{2}$ ) for $16 \mathrm{~d}$ after a 2-week carotenoid depletion period. Fasting blood samples were taken before the intervention and after 3, 6, 9,13 and 16 d. Plasma HPLC analyses allowed for determination of the concentration; liquid chromatography-MS in the single ion monitoring mode was used to confirm peak assignment. The concentrations of $\alpha$-cryptoxanthin increased significantly after only $3 \mathrm{~d}$ of supplementation. The concentration-time plots showed a characteristic shape with a first maximum after day 6, a decline until day 9 and a gradual second rise until the end of the study. Standardisation of plasma $\alpha$-cryptoxanthin concentrations to triacylglycerol or total cholesterol did not influence the characteristics. The maximum concentrations reached at the end of the intervention period ranged from 0.077 to $0.160 \mu \mathrm{mol} / \mathrm{l}$. These results suggest a high intestinal absorption and an enrichment of $\alpha$-cryptoxanthin in the plasma even from a minimally formulated cellulose-based supplement.
\end{abstract}

$\alpha$-Cryptoxanthin: Plasma xanthophyll response: Liquid chromatography-mass spectroscopy in the single ion monitoring mode: Pilot studies

Xanthophylls have attracted a lot of interest since it was presumed that an increased nutritional uptake might provide protection against certain diseases. In particular, the health benefits of lutein, zeaxanthin and $\beta$-cryptoxanthin have been well documented in the last decade. For example, the non-provitamin A xanthophylls lutein and zeaxanthin may protect the human eye from age-related macula degeneration and cataracts (Beatty et al. 1999; Mares-Perlman et al. 2002). In accordance with their high nutritional value, plants rich in lutein such as Tagetes erecta (Hadden et al. 1999; Breithaupt et al. 2002) are actually cultivated on a large scale. $\beta$-Cryptoxanthin was recently associated with an increased protein formation and/or prevention of loss of proteins in man and animals (Eichinger et al. 2005). A high plasma level of $\beta$-cryptoxanthin has also been linked to a protective effect against rheumatoid arthritis (Cerhan et al. 2003; Pattison et al. 2005) and - together with $\mathrm{Zn}$ at low concentrations to a positive effect on bone components in vitro (Uchiyama et al. 2005). Craft et al. (2004) found that $\beta$-cryptoxanthin belongs to the major xanthophylls in the human brain, where particularly the frontal cortex, which is generally susceptible to Alzheimer's disease, exhibited higher concentrations than other parts. However, a possible mode of action still remains to be elucidated.
Looking into more detail, $\beta$-cryptoxanthin is the most popular representative of a group of three structural isomers (Fig. 1). In accordance with the isoprenoid biosynthetic pathway in plants (van den Berg et al. 2000), enzymic hydroxylation of symmetric $\beta$-carotene leads to the formation of $\beta$-cryptoxanthin, whereas the same reaction starting from asymmetric $\alpha$-carotene $(\beta, \varepsilon$-carotene $)$ gives rise to two reaction products: $\beta, \varepsilon$-carotene- $3^{\prime}$-ol ( $\alpha$-cryptoxanthin) and $\beta, \varepsilon$-carotene-3-ol (zeinoxanthin). This designation is in accordance with modern xanthophyll nomenclature. However, it must be highlighted that the structural cryptoxanthin isomers $\alpha$-cryptoxanthin and zeinoxanthin were often confused in older literature, causing misinterpretation of the carotenoid content of food (Schlatterer \& Breithaupt, 2005).

Due to the presence of unsubstituted $\beta$-ionone rings, $\alpha$ - and $\beta$-cryptoxanthin act as provitamin-A precursors. $\beta$-Cryptoxanthin and zeinoxanthin are found in numerous food plants. $\beta$-Cryptoxanthin is present in high amounts in red paprika, citrus fruits, persimmon and in tropical fruits such as papaya and mango (Chandrika et al. 2003; Meléndez-Martínez et al. 2003; Collera-Zuniga et al. 2004), whereas zeinoxanthin forms a typical component of oranges and maize (MeléndezMartínez et al. 2003, 2005; Cortés et al. 2004; Schlatterer \& Breithaupt, 2005). Mercadante \& Rodriguez-Amaya (2001) 
<smiles>CC1=C(/C=C/C(C)=C/C=C/C(C)=C/C=C/C=C(C)/C=C/C=C(C)/C=C/C2=C(C)CC(O)CC2(C)C)C(C)(C)CCC1</smiles>

(B)<smiles>CC1=C[C@@H](O)CC(C)(C)[C@H]1/C=C/C(C)=C/C=C/C(C)=C/C=C/C=C(C)/C=C/C=C(C)/C=C/C1=C(C)CCCC1(C)C</smiles>

(C)<smiles>CC1=CCCC(C)(C)C1/C=C/C(C)=C/C=C/C(C)=C/C=C/C=C(C)/C=C/C=C(C)/C=C/C1=C(C)CC(O)CC1(C)C</smiles>

Fig. 1. Chemical structures of cryptoxanthin isomers: (A) $\beta$-cryptoxanthin ( $\beta, \quad \beta$-carotene-3-ol); (B) $\alpha$-cryptoxanthin $\left(\beta, \varepsilon\right.$-carotene- $\left.3^{\prime}-\mathrm{ol}\right)$; (C) zeinoxanthin $(\beta, \varepsilon$-carotene-3-ol).

pointed out that Brazilian green and leafy vegetables such as watercress, lettuce, chicory, endive and parsley contain trace amounts of $\alpha$-cryptoxanthin, but not $\beta$-cryptoxanthin as often reported. The $\alpha$-cryptoxanthin standard used by these researchers was isolated from Amaranthus viridis. However, as far as we know, the fresh green leaves of carrots serve as the only important $\alpha$-cryptoxanthin source (Müller, 1997). Health functions of $\alpha$-cryptoxanthin are essentially not known.

Since $\alpha$-cryptoxanthin is rarely found in food plants, the respective concentration in human plasma is expected to be extremely low (no reliable data available). Consequently, the use of $\alpha$-cryptoxanthin as a marker xanthophyll allows the determination of the intestinal absorption without interference caused by minor xanthophylls in HPLC analyses. Thus, for the first time, a pilot human intervention study was designed using a cellulose-based $\alpha$-cryptoxanthin formulation without further additives. The supplement was administered in gelatin soft-gel capsules in multiple doses of $156 \mu \mathrm{g} / \mathrm{d}$ to three male volunteers for $16 \mathrm{~d}$ and fasting blood samples were analysed before and after 3, 6, 9, 13 and $16 \mathrm{~d}$.

\section{Experimental design}

\section{Materials}

Light petroleum (boiling fraction $40-60^{\circ} \mathrm{C}$ ), methanol, acetone, ethyl acetate, ethanol, diethyl ether, $n$-hexane, silica gel 60 (0.063-0.200 mm) and 2,6-di-tert-butyl-p-cresol were purchased from Merck (Darmstadt, Germany). Methyl tert-butyl ether (MTBE) and $\mathrm{KOH}$ (pellets > $>5 \%$ ) were from Sigma-Aldrich (Taufkirchen, Germany). All solvents were distilled before use. Ultra-pure water was obtained from a Milli-Q 185 apparatus (Millipore, Eschborn, Germany). $\beta$-Apo-12'-carotenal (standard) was generously provided by BASF (Ludwigshafen, Germany), $\beta$-cryptoxanthin was a gift from DSM (Kaiseraugst, Switzerland), anhydrolutein I ( $3^{\prime}, 4^{\prime}$ didehydro- $\beta, \gamma$-carotene-3-ol) was obtained from CaroteNature (Lupsingen, Switzerland) and zeinoxanthin was isolated from canned maize (Zea mays) as described previously (Schlatterer \& Breithaupt, 2005). Cellulose powder (Elcema P100 ${ }^{\circledR}$ ) was obtained from Synopharm (Barsbüttel, Germany). The test kits for in vitro determination of plasma triacylglycerol (method TR210) or cholesterol (method CH200) were purchased from Randox Laboratories GmbH (Krefeld, Germany). Carrot leaves from ecological production were obtained from the Research Station for Husbandry and Organic Farming, University of Hohenheim (Stuttgart, Germany).

\section{Subjects}

Three male individuals aged 22, 29 and 31 years (age 27.3 (SD $4.7)$ years; BMI $\left.21.6(\mathrm{SD} 0.3) \mathrm{kg} / \mathrm{m}^{2}\right)$ were recruited from staff and students of the Institute of Food Science (Hannover, Germany). The characteristics of the participants are summarised in Table 1. None of them suffered from gastrointestinal diseases or took laxatives or drugs lowering plasma triacylglycerol or cholesterol concentrations. Participants were requested to keep a normal diet but to avoid xanthophyll-rich food such as oranges, peaches, red paprika, papaya, fruit juices, xanthophyll-containing dietary supplements and vitamin-fortified beverages during the depletion period and during the intervention study. The protocol was approved by the Medical Ethics Committee of the Medizinische Hochschule (Hannover, Germany). All participants provided written informed consent.

\section{Study design}

The study was designed as a human pilot intervention study and consisted of a 2-week depletion period followed by a $16 \mathrm{~d}$ intervention phase. After taking the first fasting plasma sample, participants received a breakfast and took the first supplement under supervision afterwards. Before leaving, each participant received fifteen capsules in a closed plastic box and was advised to take one of them after the individual breakfast each morning together with some water. All

Table 1. Characteristics of the three participants

(Mean values and standard deviations)

\begin{tabular}{|c|c|c|c|c|c|c|c|c|}
\hline \multirow[b]{2}{*}{ Participant } & \multirow[b]{2}{*}{ Age (years) } & \multirow[b]{2}{*}{ Weight (kg) } & \multirow[b]{2}{*}{ Height (m) } & \multirow[b]{2}{*}{$\mathrm{BMI}\left(\mathrm{kg} / \mathrm{m}^{2}\right)$} & \multicolumn{2}{|c|}{$\begin{array}{l}\text { Triacylglycerol } \\
(\mathrm{mmol} / \mathrm{l})^{\star}\end{array}$} & \multicolumn{2}{|c|}{$\begin{array}{l}\text { Cholesterol } \\
(\mathrm{mmol} / \mathrm{l})^{\star}\end{array}$} \\
\hline & & & & & Mean & SD & Mean & $\mathrm{SD}$ \\
\hline 1 & 31 & $70 \cdot 0$ & 1.79 & $21 \cdot 8$ & 0.62 & 0.12 & $4 \cdot 83$ & 0.76 \\
\hline 2 & 29 & $60 \cdot 4$ & 1.69 & $21 \cdot 2$ & 0.95 & 0.19 & $4 \cdot 70$ & 0.55 \\
\hline 3 & 22 & $59 \cdot 8$ & $1 \cdot 66$ & $21 \cdot 7$ & 0.80 & 0.11 & $5 \cdot 28$ & 1.56 \\
\hline
\end{tabular}

* Six determinations per participant.

For details of subjects and procedures, see this page. 
participants were instructed to store the box in a refrigerator at $4^{\circ} \mathrm{C}$. Further fasting blood samples were taken in the morning after $3,6,9,13$ and $16 \mathrm{~d}$.

\section{Preparation of supplements}

Isolation of $\alpha$-cryptoxanthin from carrot leaves. Fresh green carrot leaves $(2.6 \mathrm{~kg}$, without thick stems) from ecological production were homogenised in samples using a bowl cutter SL11 (cutter spindle $1400 \mathrm{rpm}$, bowl $19 \mathrm{rpm}$; $1 \mathrm{~min}$; ADE, Hamburg, Germany). The resulting mush was filled in samples of $200 \mathrm{~g}$ into glass columns $(550 \times 30 \mathrm{~mm})$ and the carotenoids were extracted by a mixture of methanol-ethyl acetate-light petroleum (1:1:1, by vol.; 1 litre per column). To allow for phase separation, the extract was mixed with water $(100 \mathrm{ml})$. All organic phases were combined, the solvent was evaporated in vacuum $\left(30^{\circ} \mathrm{C} ; 50 \mathrm{mbar}\right)$ and the residue dissolved in diethyl ether $(600 \mathrm{ml})$.

Saponification. For removal of lipids and chlorophylls, the oily residue was dissolved in diethyl ether and saponified overnight using methanolic $\mathrm{KOH}(30 \%$, w/v; $10 \mathrm{ml}$ per $100 \mathrm{ml}$ ether). To remove alkali, the ether phase was washed and evaporated again $\left(30^{\circ} \mathrm{C} ; 50 \mathrm{mbar}\right)$. The residue was dissolved in light petroleum and subjected to flash chromatography (glass column $400 \times 20 \mathrm{~mm})$ on silica gel $(10 \mathrm{~g})$ suspended in light petroleum. Samples of $10 \mathrm{ml}$ were poured onto the column head. The first band, obtained by elution with light petroleum, consisted mainly of $\beta$-carotene and was discarded. The second band obtained by elution with light petroleum-acetone $(95: 5, \mathrm{v} / \mathrm{v})$ was collected, the solvent completely removed $\left(30^{\circ} \mathrm{C} ; 50\right.$ mbar) and the residue dissolved in ethanol $(210 \mathrm{ml})$. Liquid chromatography (LC)-MS analyses using an atmospheric pressure chemical ionisation interface operated in the positive mode proved the main carotenoid to be $\alpha$-cryptoxanthin (Schlatterer \& Breithaupt, 2005). Thus, $10 \mathrm{mg} \alpha$-cryptoxanthin $/ 210 \mathrm{ml}$ ethanol were obtained.

Preparation of capsules. Cellulose powder $(5 \cdot 5 \mathrm{~g})$ was suspended in $200 \mathrm{ml}$ of the ethanolic $\alpha$-cryptoxanthin stock solution in a round-bottomed flask. The solvent was evaporated slowly $\left(30^{\circ} \mathrm{C} ; 50 \mathrm{mbar}\right)$ until a dry free-flowing powder was obtained. Samples of exactly $100 \mathrm{mg}$ were filled manually in gelatin capsules. Thus, fifty-four capsules were prepared.

Quantification of $\alpha$-cryptoxanthin. The $\alpha$-cryptoxanthin concentration of the capsules was determined after solvent extraction with methanol-ethyl acetate-light petroleum (1:1:1, by vol.) by HPLC. Due to similar molar extinction coefficients, a $\beta$-cryptoxanthin calibration graph was applied for quantification of $\alpha$-cryptoxanthin. The graph was generated by plotting $\beta$-cryptoxanthin peak areas (milli absorption units) $v$. the respective concentrations (range $1.08-21.52 \mathrm{mg} / \mathrm{l}$ ). An $\alpha$-cryptoxanthin concentration of $156 \cdot 3$ (SD 4.9) $\mu \mathrm{g} /$ capsule ( $n$ 3) was determined. The stability of $\alpha$-cryptoxanthin was verified at the end of the study with additional capsules. A loss of $2.8 \%$ after $16 \mathrm{~d}$ storage at $4^{\circ} \mathrm{C}(n)$ ) was observed. As this stability was regarded as sufficient for the intervention period no further antioxidants (for example, $\alpha$-tocopherol) were added.

\section{Plasma sample preparation}

Conventional procedure. At any blood withdrawal, at least $10 \mathrm{ml}$ were sampled from each participant. Immediately after collection, the plasma was obtained by centrifugation $\left(2000 \mathrm{~g} ; 19^{\circ} \mathrm{C} ; 10 \mathrm{~min}\right)$ and stored at $-20^{\circ} \mathrm{C}$ in plastic caps. The work-up procedure was based on a method of Khachik et al. (1997). In brief, $1.5 \mathrm{ml}$ plasma were precipitated with ethanol ( $1 \mathrm{ml}$ containing $1 \%$ 2,6-di-tert-butyl-pcresol $(\mathrm{w} / \mathrm{v})$ ) and mixed on a shaker (1 min). An aliquot $(0.1 \mathrm{ml})$ of an ethanolic $\beta$-apo- $12^{\prime}$-carotenal standard $(20 \mu \mathrm{g} / \mathrm{ml})$ was added and the solution was mixed again. To extract the carotenoids, $3 \mathrm{ml} n$-hexane were added. The mixture was stirred, the precipitate was spun down using a centrifuge $\left(644 \mathrm{~g} ; 10^{\circ} \mathrm{C} ; 5 \mathrm{~min}\right)$, the organic layer was transferred into a $10 \mathrm{ml}$ brown glass vial, and the extraction procedure was repeated. The combined organic phases were evaporated, the residue dissolved in $0.8 \mathrm{ml}$ MTBEmethanol $(1: 1, \mathrm{v} / \mathrm{v})$, passed through a $0.45 \mu \mathrm{m}$ membrane filter and subjected to HPLC-variable wavelength detector analysis. To determine possible losses during the work-up procedure, the HPLC peak areas of the standard were monitored. The recovery of $\beta$-apo- $12^{\prime}$-carotenal from extractions of all plasma samples accounted for 103 (SD 6)\% (n 18). Plasma triacylglycerol and total cholesterol were measured manually by using commercial in vitro enzymic test kits.

Extract for liquid chromatography-mass spectroscopy in the single ion monitoring mode analysis. To verify $\alpha$-cryptoxanthin identification, one large plasma sample of participant $3(5 \mathrm{ml})$ was extracted three times with a ternary mixture of methanol, ethyl acetate and light petroleum (1:1:1, by vol.; $30 \mathrm{ml}$ each). The solvent was removed $\left(30^{\circ} \mathrm{C}, 50 \mathrm{mbar}\right)$ and the dry residue was saponified as described earlier ( $1 \mathrm{ml}$ methanolic $\mathrm{KOH}(30 \%$, w/v) $-10 \mathrm{ml}$ diethyl ether) to remove interfering lipids. The residue was dissolved in $1.0 \mathrm{ml}$ MTBE-methanol $(1: 1, \mathrm{v} / \mathrm{v})$, passed through a $0.45 \mu \mathrm{m}$ membrane filter and subjected to LC-MS analysis in the single ion monitoring (SIM) mode.

\section{Analysis and chromatography}

The HPLC consisted of a modular system HP1100 (HewlettPackard GmbH, Waldbronn, Germany) with the variable wavelength detector set to $450 \mathrm{~nm}$. For carotenoid separation, a C30 column $(250 \times 4.6 \mathrm{~mm}$ internal diameter; $5 \mu \mathrm{m}$; YMC Europe, Schermbeck, Germany) including a pre-column $(10 \times 4.0 \mathrm{~mm}$ internal diameter; $5 \mu \mathrm{m})$ was used and kept at $35^{\circ} \mathrm{C}$. LC-MS was performed on an HP1100 modular HPLC system, coupled to a Micromass (Manchester, UK) VG platform II quadrupole mass spectrometer equipped with an atmospheric pressure chemical ionisation interface, operating in the positive mode (scan range $\mathrm{m} / \mathrm{z}$ 300-700; data processing by MassLynx 3.2). The mobile phase consisted of mixtures of methanolMTBE-water (81:15:4, by vol. (A) and 6:90:4, by vol. (B)), starting with $99 \%$ A, followed by a gradient to obtain $44 \% \mathrm{~A}$ at $39 \mathrm{~min}, 0 \% \mathrm{~A}$ at $45 \mathrm{~min}, 99 \% \mathrm{~A}$ at $50 \mathrm{~min}$ and isocratic $99 \%$ A from $50-55 \mathrm{~min}$ at a flow rate of $1 \mathrm{ml} / \mathrm{min}$. For LC-MS(SIM) analysis, the following settings were used: selected mass, $535.4 \mathrm{Da}$; dwell time, $0.2 \mathrm{~s}$; inter-channel delay, $0.02 \mathrm{~s}$; span, $0.2 \mathrm{Da}$; injection volume, $30 \mu \mathrm{l}$. Further MS parameters have been detailed previously (Breithaupt et al. 2002). 


\section{Results}

Representative HPLC analyses of samples of the fractionated extract obtained from carrot leaves proved that $\alpha$-cryptoxanthin was the main xanthophyll, accompanied by small amounts of $\alpha$ - and $\beta$-carotene, which were co-extracted. Due to their low concentration (35 $\mu$ g $\beta$-carotene/capsule; $n$ 3) it was anticipated that both would probably not compete with excess $\alpha$-cryptoxanthin and thus should not affect absorption kinetics remarkably. Identification of $\alpha$-cryptoxantin was based on its characteristic absorption spectrum (424(sh)/446/ $474 \mathrm{~nm}$, determined online in the HPLC solvents), the retention time and the typical fragmentation pattern found in LC-MS experiments: the respective mass spectrum showed a quasimolecular ion at $\mathrm{m} / z 553.4\left(\mathrm{M}+\mathrm{H}^{+}\right)$with low relative abundance $(9 \%)$ and one daughter ion at $\mathrm{m} / \mathrm{z}$ 535.4 (M + H$\mathrm{H}_{2} \mathrm{O}^{+}$) with high intensity $(100 \%)$. The loss of water from the quasimolecular ion occurs readily, a phenomenon typical for xanthophylls bearing at least one hydroxylated $\varepsilon$-ionone ring (Mercadante \& Rodriguez-Amaya, 2001; Schlatterer \& Breithaupt, 2005). Thus, LC-MS studies clearly supported the assignment of $\alpha$-cryptoxanthin.

Figure 2 depicts extended sections of HPLC chromatograms of representative plasma samples (participant 3; Table 1) before (trace A) and after supplementation for $16 \mathrm{~d}$ (trace B). An additional trace $\mathrm{C}$ shows the same extract as trace $\mathrm{B}$ spiked with $\alpha$-cryptoxanthin. Trace A proves that the fasting plasma sample extract contains neither $\alpha$-cryptoxanthin nor another xanthophyll co-eluting at the expected retention time. In particular, the retention time difference between $\alpha$ - and $\beta$-cryptoxanthin $(1.5 \mathrm{~min})$ was definitely high enough to avoid peak overlapping $(R 5 \cdot 0)$. Although other common plasma carotenes and xanthophylls appeared in the chromatograms, they did not interfere with the separation of cryptoxanthin isomers. Their assignment was based on the respective absorption spectra and the quasimolecular ions. Particularly, zeinoxanthin and anhydrolutein I ( $3^{\prime}, 4^{\prime}$-didehydro- $\beta, \gamma$-carotene- 3 -ol), a metabolite of lutein usually found in human plasma (Khachik et al. 1995), did not co-elute. Thus, quantification of $\alpha$-cryptoxanthin could be accomplished without baseline correction. Peak assignment was further assured by LC-MS analyses of a concentrated and saponified plasma sample of participant 3 (Table 1); to enhance sensitivity, the interface was operated in the SIM mode, using $\mathrm{m} /$ $z 535.4$ to scan for the typical $\alpha$-cryptoxanthin fragment ion. The respective trace is depicted in insert D (Fig. 2), unequivocally proving correct assignment of $\alpha$-cryptoxanthin (2). The high sensitivity of the LC-MS(SIM) analysis applied is obvious if the $\alpha$-cryptoxanthin concentration in the concentrated sample $(0 \cdot 34 \mu \mathrm{mol} / \mathrm{l})$ and a SIM-signal:noise level of 3:1 are considered; the SIM technique allows for unequivocal determination of concentrations up to $0 \cdot 1 \mu \mathrm{mol} / \mathrm{l}(55 \mu \mathrm{g} / \mathrm{l})$, corresponding to a plasma amount of $20 \mathrm{nmol} / \mathrm{l}(11 \mu \mathrm{g} / \mathrm{l})$.

For quantitative assessment, plasma concentration-time curves $(\mu \mathrm{mol} / 1 v$. d) of all three participants were constructed (Fig. 3(A)). In each case, the plasma concentrations increased significantly after $3 \mathrm{~d}$ of supplementation. The concentrationtime plots of each individual showed an early maximum after $6 \mathrm{~d}$, a decline in concentration until day 9 and a gradual second rise until the end of the study. Maximum concentrations reached at the end of the intervention period were $0.077,0.160$ and $0.157 \mu \mathrm{mol} / \mathrm{l}$, respectively.

To estimate the intestinal absorption of $\alpha$-cryptoxanthin from the supplement, two assumptions were considered: (i) $4 \%$ of the body weight is plasma (Barua, 1999); (ii) after an initial phase of about $13 \mathrm{~d}$, a final steady state can be reached. Such a plateau was recently ascertained by Hartmann et al. (2004) after giving multiple doses of zeaxanthin $(1 \mathrm{mg} / \mathrm{d}$ for $42 \mathrm{~d}$ ) after a booster period of about 2 weeks. Taking into account that a plasma xanthophyll plateau is in function not only of the time of supplementation but also of the amount supplied (which is rather low in the present study), the time required to reach a plateau is probably more that $16 \mathrm{~d}$. For example, Olmedilla et al. (2002) described the plateau formation after 4 weeks upon supplementation with several carotenoids. However, based on a mean concentration of $0.131 \mu \mathrm{mol} / \mathrm{l}$ and a mean plasma mass of 2.54 litres (three

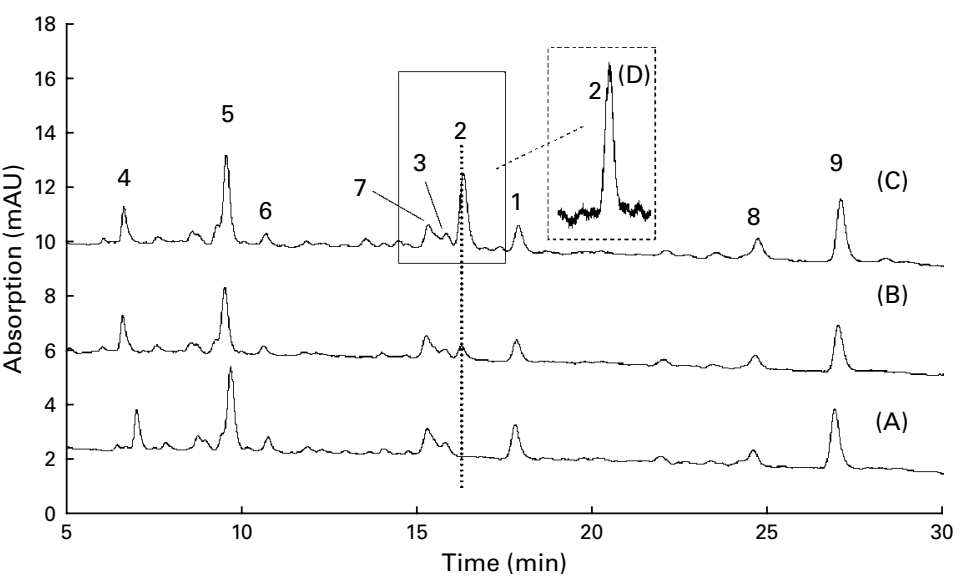

Fig. 2. HPLC chromatograms (extended sections; variable wavelength detector, $450 \mathrm{~nm}$ ) of representative plasma samples originating from participant 3 (Table 1) (milli absorption units; mAU): (A) before supplementation; (B) after the intervention (16d). Trace (C) corresponds to the plasma sample spiked with $\alpha$ cryptoxanthin. The insert (D) represents the relevant section of the mass trace $(\mathrm{m} / \mathrm{z} 535.4)$, suitable for identification of $\alpha$-cryptoxanthin in liquid chromatographyMS in single ion monitoring mode analysis, determined in a concentrated and saponified sample extract ( $5 \mathrm{ml}$ plasma/1 ml final volume) of participant 3 . Peak assignment: $1, \beta$-cryptoxanthin; 2, $\alpha$-cryptoxanthin; 3 , zeinoxanthin; 4, $\beta$-apo-12'-carotenal (standard); 5 , lutein; 6 , zeaxanthin; 7 , anhydrolutein I (3',4'-didehydro$\beta, \gamma$-carotene-3-ol); $8, \alpha$-carotene; $9, \beta$-carotene. For details of subjects and procedures, see p. 372. 

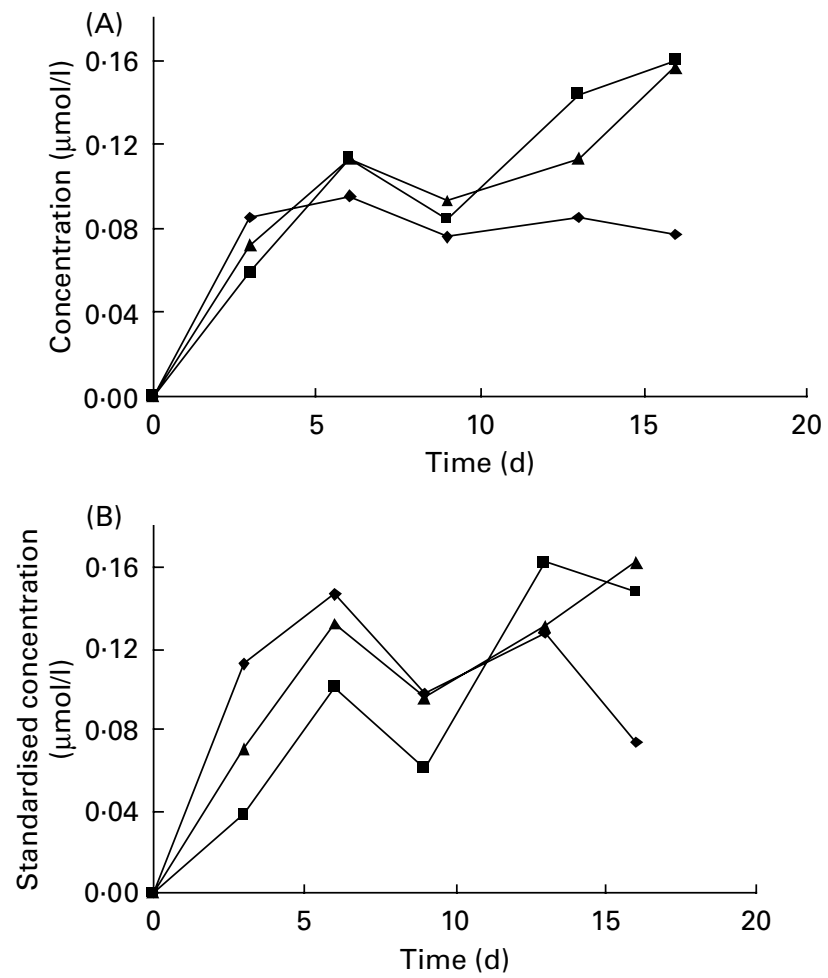

Fig. 3. Plasma concentrations of $\alpha$-cryptoxanthin studied in dependence of the sampling time ( $\mu \mathrm{mol} / \mathrm{l} v$. d) after taking sixteen capsules containing $156 \mu \mathrm{g} \alpha$-cryptoxanthin each by three male individuals $(\boldsymbol{\square}, \boldsymbol{\Lambda}, \bullet)$ : (A) without standardisation; (B) standardised to triacylglycerol plasma concentrations. For details of subjects and procedures, see p. 372 .

each), the participants had a mean total amount of $0.333 \mu$ mol $(184 \mu \mathrm{g}) \alpha$-cryptoxanthin in their circulating plasma after sixteen doses of the supplement. As only $156 \mu \mathrm{g}$ were administered per d, this amount points to both an efficient absorption of the xanthophyll and even to an enrichment of $\alpha$-cryptoxanthin in the human plasma (the clearance period of a single dose may be 2-3 weeks; Novotny et al. 2005; Tang et al. 2005). Thus, the results of the present pilot study suggest a high intestinal absorption of $\alpha$-cryptoxanthin even from a minimally formulated cellulose-based supplement.

To account for potential variations in the triacylglycerol or total cholesterol levels, $\alpha$-cryptoxanthin concentrations were corrected; each $\alpha$-cryptoxanthin value was divided by the corresponding triacylglycerol or total cholesterol value and multiplied by the mean triacylglycerol or total cholesterol concentration of all participants. Both triacylglycerol and total cholesterol concentrations were in the normal range for all human subjects (desirable concentrations: triacylglycerol $(<1.25 \mathrm{mmol} / \mathrm{l}$; total cholesterol $(<5.18 \mathrm{mmol} / \mathrm{l}$; Jordan et al. 1995; see Table 1 for mean values). $\alpha$-Cryptoxanthin plasma responses adjusted for triacylglycerol are shown in Fig. 3 (B). The time course of triacylglycerol- and total cholesterol-corrected $\alpha$-cryptoxanthin concentrations resembled that of the uncorrected plots. Thus, standardisation did not influence the shape of the curves.

Areas under the curve $(0-16 \mathrm{~d} ; \mu \mathrm{mol} \times \mathrm{d} / \mathrm{l})$ were determined by the trapezoidal rule without baseline area correction (SigmaPlot). The respective areas under the curve $(0-16 \mathrm{~d})$ values, calculated from the adjusted concentration-time plots, were as follows (for participant 1, 2 and 3 respectively): $1.676,1.423$ and 1.644 (standardised to triacylglycerol); 1.329 , 1.691 and 1.305 (standardised to total cholesterol). Since area under the curve values are regarded as proportional to the bioavailability (Yao et al. 2000), comparison of the triacylglycerol- or cholesterol-adjusted values indicated that there were only small variations among subjects in the intestinal absorption of $\alpha$-cryptoxanthin given in multiple doses.

\section{Discussion}

For isolation of $\alpha$-cryptoxanthin, fresh green carrot leaves from ecological production were used. Since these plants were cultivated without the application of pesticides, the leaf extract did not contain anthropogenic compounds with a possible health risk for participants. However, the amount of $\alpha$ cryptoxanthin available was very limited $(3.8 \mathrm{mg} / \mathrm{kg}$ leaves $)$. As a consequence, only three participants were included in the pilot study, designed to acquire basic data about the intestinal absorption of $\alpha$-cryptoxanthin administered as multiple oral doses. Although $\alpha$-cryptoxanthin is usually not present as a major xanthophyll in the human diet and the resulting plasma levels are consequently extremely low, a 2-week depletion phase preceded the study to reduce the overall carotenoid concentrations usually found in plasma to a base level and to approximate the individual levels of the participants.

Xanthophylls are lipid soluble and follow the same absorption pathway as other dietary lipids. Absorption of xanthophylls occurs via incorporation into chylomicrons, which subsequently enter the bloodstream. As $\alpha$-cryptoxanthin represents a comparatively polar carotenoid (one hydroxyl function), it is distributed approximately equally between the HDL and LDL fractions (Furr \& Clark, 1997). After daily ingestion of $\alpha$-cryptoxanthin supplements, plasma concentration of all participants increased continuously except for a slight decrease on day 9 , indicating that all participants were responders. We have no explanation for this temporary decrease. Due to the time lag it cannot be explained by hepatic circulation and lipoprotein incorporation, as is known for the biphasic plasma response to $\beta$-carotene within $2 \mathrm{~d}$ (Rock, 1997). Furthermore, we do not think that the decrease is a consequence of ingestion of 'banned' carotenoid-rich food possibly leading to a competing effect, since it was observed in all plasma samples. The second increase found in the $\alpha$-cryptoxanthin concentration cannot be explained by ingestion of food rich in $\alpha$-cryptoxanthin because this xanthophyll usually forms a minor component and is present in the European diet in extremely low amounts. Moreover, we do not believe that it is an analytical artefact because all analytical steps were controlled accurately. A second peak, which is usually observed in concentration-time plots because xanthophylls are incorporated in VLDL and LDL, did not appear in the present study.

It is understood that the low number of subjects $(n 3)$ is a limitation of the present study. However, the variance in plasma response between individual subjects (see Fig. 3) was quite low, a finding being in contrast to results of former studies reporting broad interindividual variations for other carotenoids. One explanation may be that all subjects were male and were within the same age range (27.3 (SD 4.7) years). 
The results of the present pilot study for the first time suggest a high intestinal absorption of $\alpha$-cryptoxanthin even from a minimally formulated cellulose-based supplement. Although potential health functions of $\alpha$-cryptoxanthin have not yet been investigated, this xanthophyll may serve as a future dietary supplement with both vitamin A activity and further biological values, not yet known. After optimisation of the extraction step from carrot leaves - which usually are regarded as plant waste material - there is a virtual possibility to launch an optimised formulation on the market.

\section{Acknowledgements}

We want to express our sincere thanks to the volunteers of the Institute of Food Science, University of Hannover, Germany. We appreciate highly the excellent working conditions at the Institute of Food Chemistry at the University of Hohenheim, Stuttgart, Germany.

\section{References}

Barua AB (1999) Intestinal absorption of epoxy- $\beta$-carotenes by humans. Biochem J 339, 359-362.

Beatty S, Boulton M, Henson D, Koh H-H \& Murray IJ (1999) Macular pigment and age-related macular degeneration. $\mathrm{Br} J$ Ophthalmol 83, 867-877.

Breithaupt DE, Wirt U \& Bamedi A (2002) Differentiation between lutein monoester regioisomers and detection of lutein diesters from marigold flowers (Tagetes erecta L.) and several fruits by liquid chromatography-mass spectrometry. J Agric Food Chem 50, 66-70.

Cerhan JR, Saag KM, Merlino LA, Mikuls TR \& Criswell LA (2003) Antioxidant micronutrients and risk of rheumatoid arthritis in a cohort of older women. Am J Epidemiol 157, 345-354.

Chandrika UG, Jansz ER, Wickramasinghe SMDN \& Warnasuriya ND (2003) Carotenoids in yellow- and red-fleshed papaya (Carica papaya L.). J Sci Food Agric 83, 1279-1282.

Collera-Zuniga O, Garcia JF \& Melendez GR (2004) Comparative study of carotenoid composition in three Mexican varieties of Capsicum annuum L. Food Chem 90, 109-114.

Cortés C, Esteve MJ, Frígola A \& Torregrosa F (2004) Identification and quantification of carotenoids including geometrical isomers in fruit and vegetable juices by liquid chromatography with ultraviolet-diode array detection. J Agric Food Chem 52, 2203-2212.

Craft NE, Haitema TB, Garnett KM, Fitch KA \& Dorey CK (2004) Carotenoid, tocopherol, and retinol concentrations in elderly human brain. J Nutr Health Aging 8, 156-162.

Eichinger A, Goralczyk R, Wertz K \& Wyss A (2005) Use of $\beta$-cryptoxanthin. PCT Int. Appl. pp. 21, WO 2005/110122A1. Internation publication date 24/11/2005.

Furr HC \& Clark RM (1997) Intestinal absorption and tissue distribution of carotenoids. Nutr Biochem 8, 364-377.

Hadden WL, Watkins RH, Levy LW, Regalado E, Rivadeneira DM, van Breemen RB \& Schwartz SJ (1999) Carotenoid composition of marigold (Tagetes erecta) flower extract used as nutritional supplement. J Agric Food Chem 47, 4189-4194.

Hartmann D, Thürmann PA, Spitzer V, Schalch W, Manner B \& Cohn W (2004) Plasma kinetics of zeaxanthin and $3^{\prime}$-dehydrolutein after multiple oral doses of synthetic zeaxanthin. Am J Clin Nutr 79, 410-417.
Jordan P, Brubacher D, Moser U, Stähelin HB \& Gey KF (1995) Vitamin $\mathrm{E}$ and vitamin A concentrations in plasma adjusted for cholesterol and triacylglycerides by multiple regression. Clin Chem 41, 924-927.

Khachik F, Englert G, Beecher GR \& Smith JC Jr (1995) Isolation, structural elucidation, and partial synthesis of lutein dehydration products in extracts from human plasma. J Chromatogr 670B, 219-233.

Khachik F, Spangler CJ \& Smith JC Jr (1997) Identification, quantification, and relative concentrations of carotenoids and their metabolites in human milk and serum. Anal Chem 69, $1873-1881$.

Mares-Perlman JA, Millen AE, Ficek TL \& Hankinson SE (2002) The body of evidence to support a protective role for lutein and zeaxanthin in delaying chronic disease. J Nutr 132, $518 \mathrm{~S}-524 \mathrm{~S}$.

Meléndez-Martínez AJ, Britton G, Vicario IM \& Heredia FJ (2005) Identification of zeinoxanthin in orange juices. $J$ Agric Food Chem 53, 6362-6367.

Meléndez-Martínez AJ, Vicario IM \& Heredia FJ (2003) A routine high-performance liquid chromatography method for carotenoid determination in ultrafrozen orange juices. J Agric Food Chem 51, 4219-4224.

Mercadante AZ \& Rodriguez-Amaya D (2001) Confirmation of the identity of $\alpha$-cryptoxanthin and incidence of minor provitamin A carotenoids in green leafy vegetables. Cienc Tecnol Aliment 21, 216-222.

Müller H (1997) Determination of the carotenoid content in selected vegetables and fruit by HPLC and photodiode array detection. Z Lebensm Unters Forsch 204, 88-94.

Novotny JA, Kurilich AC, Britz SJ \& Clevidence BA (2005) Plasma appearance of labeled $\beta$-carotene, lutein, and retinol in humans after consumption of isotopically labeled kale. J Lipid Res 46, 1896-1903.

Olmedilla B, Granado F, Southon S, et al. (2002) A European multicentre, placebo-controlled supplementation study with $\alpha$-tocopherol, carotene-rich palm oil, lutein or lycopene: analysis of serum responses. Clin Sci 102, 447-456.

Pattison DJ, Symmons DPM, Lunt M, Welch A, Bingham SA, Day NE \& Silman AJ (2005) Dietary $\beta$-cryptoxanthin and inflammatory polyarthritis: results from a population-based prospective study. Am J Clin Nutr 82, 451-455.

Rock CL (1997) Carotenoids: biology and treatment. Pharmacol Ther 75, 185-197.

Schlatterer J \& Breithaupt DE (2005) Cryptoxanthin structural isomers in oranges, orange juice and other fruits. J Agric Food Chem 53, 6355-6361.

Tang G, Qin J, Dolnikowski GG, Russel RM \& Grusak MA (2005) Spinach or carrots can supply significant amounts of vitamin A as assessed by feeding with intrinsically deuterated vegetables. Am J Clin Nutr 82, 821-828.

Uchiyama S, Ishiyama K, Hashimoto K \& Yamaguchi M (2005) Synergistic effect of $\beta$-cryptoxanthin and zinc sulfate on the bone component in rat femoral tissues in vitro. Biol Pharm Bull 28, 2142-2145.

van den Berg H, Faulks R, Granado HF, Hirschberg J, Olmedilla B, Sandmann G, Southon S \& Stahl W (2000) The potential for the improvement of carotenoid levels in foods and the likely systemic effects. J Sci Food Agric 80, 880-912.

Yao L, Liang Y, Trahanovsky WS, Serfass RE \& White WS (2000) Use of a 13C tracer to quantify the plasma appearance of a physiological dose of lutein in humans. Lipids 35, 339-348. 